\title{
obituary
}

\section{A. D. Gardner}

Professor Arthur Duncan Gardner, a bacteriologist whose career was centred in Oxford, died on 28 January 1978 at the age of 93.

He was educated at Rugby and University College, Oxford, where he originally read law before changing to medicine. $\mathrm{He}$ qualified from $\mathrm{St}$ Thomas's Hospital in 1911, took his Fellowship of the Royal College of Surgeons, was made a lecturer in pathology, and was awarded the Radcliffe Travelling Fellowship in 1914. During the first world war he served for a time with the British Red Cross in France, and in 1915 was appointed to the directorship of the Standards Laboratory that had been newly established at Oxford by the Medical Research Council.

One of his chief functions was to supply the military and naval forces with reagents for the diagnosis of typhoid and paratyphoid fevers. This was made possible by adopting the standard killed agglutinating suspensions devised by Georges Dreyer in place of the usual living organisms. These were soon supplemented by six dysentery suspensions with their corresponding antisera for use in Salonica. The discovery of flagellar and somatic antigens and of specific and non-specific phases in organisms of the Salmonella group showed that the preparation of standard suspensions was far more complex than Dreyer had foreseen, and demanded the use of suspensions containing only the somatic antigen. Reagents for the diagnosis of brucella infections, typhus fever, and meningitis followed in due course. In 1936 Gardner was made Reader with the title of Professor, and in 1939 gave place as director of the Standards Laboratory to Lt-Col. R. F. Bridges. During the thirties, Gardner with P. H. Leslie greatly clarified the antigenic structure of the whoopingcough bacillus by defining four phases, which they named I,II,III, and IV. With Venkatraman he performed a similar function in showing the occurrence of six subgroups in the cholera-eltor-non-agglutinable group of vibrios, characterized by different $O$ antigens, only the $O$ antigen of subgroup I being specific for the diagnosis of cholera.

Gardner will also be remembered for his participation in the original work, with Florey and Chain, on penicillin at
Oxford. Not only was he responsible for determining the susceptiblity of different bacterial species to penicillin, but he was the first to give a clue to the mode of action of penicillin by demonstrating its interference with growth and division, rather than, as was commonly supposed, by killing the mature organisms.

A new, and final phase in his career opened in 1948 with his appointment to the Regius Chair of Medicine at Oxford. (This was the first of three appointments in which laboratory workers attained a high office usually held by practising physicians, the others being that of Sir Lionel Whitby, a haematologist, to the Regius Chair of Medicine at Cambridge, and of $\mathrm{Sir}$ Charles Dodds, a chemical pathologist, to the Presidency of the Royal College of Physicians of London-surely a unique conjunction and a feather in the cap of laboratory medicine.) This new task, undertaken at a difficult time, when the future of the clinical school was at stake and the National Health Service had just come into being, afforded greater scope for Gardner's personal qualities of charm, tact, and determination. In his six-year tenure of office ending with his retirement in 1954 at the age of 70 he achieved much and gained the respect and admiration of all those with whom he had to deal.

L. P. Garrod

\section{Rudolf Kompfner}

Professor RudOLF Kompfner, the electrical engineer and physicist, died on 3 December, 1977.

He was born in 1909 in Vienna where he trained as an architect. After coming to England in 1934 and practising until 1941, he went to the Physics Department of the University of Birmingham where he worked with the Admiralty group on microwave radar. While there he invented the travelling wave tube (TWT), a microwave amplifier of great importance.

In 1944 he joined the Clarendon Laboratory in Oxford. My colleague Don Walsh recalls Rudi's visits to the Services Electronics Research Laboratory in Baldock with a view to developing a medium power X-band TWT. Don's first attempt to make this tube floundered as it proved impossible to get any of the cathode current to complete the journey through to the collector. Rudi recounted how he had had the same problem with his first
TWT. He had tried very hard to measure the current reaching the end of the helix structure eventually borrowing the most sensitive galvanometer in Birmingham University to measure it. He eventually realised that stray magnetic fields were affecting the bcam focusing so he surrounded the tube with screening and almost immediately burnt out the most sensitive galvonometer in Birmingham University. In fact with his very first tube he was able to measure gain and confirm its dependence on electron velocity.

In 1951 Rudi left Oxford to join Bell Telephone Laboratories. Here he invented the backward-wave oscillator, his second major invention, and was responsible for the Telstar communications satellite and important work in radio astronomy. He was also involved in much work in the fields of lasers and optical communications.

In 1973 he retired from Bell Laboratories and for three years spent half of each year as Professor of Engineering at Oxford University and the rest of his time as Professor in the Applied Physics Department of Stanford University. At Oxford he initiated work in varic'ss applications of lasers including a . ' nning optical microscope, optical fibres and holography, and it is in this research that I first became acquainted with him. I feel very privileged to have worked with such a great man. He had a rare quality of being able to inspire those around him with his enthusiasm, and on a number of occasions I was very late home after getting thoroughly engrossed in a long discussion about some technical matter. His analyses relied heavily on graphical constructions, which presumably stemmed from his architectural training, and he kept beautiful notebooks with details of all his work. He spent most of the day just sitting at his desk inventing (as he once said "Every now and then I have a little idea") although he was also a careful experimentalist. Eventually, because of our tax laws, he was forced to spend only three months in England each year although he still continued to provide us with guidance and plenty of ideas. At Stanford he worked on other novel methods of microscopy including the scanning acoustic microscope which uses acoustic radiation to produce submicron resolution.

$\mathrm{He}$ was a fellow of the former 